\title{
Role of Rosiglitazone as a Gastroprotective Agent Against Indomethacin-Induced Gastric Mucosal Injury in Rats
}

\author{
Ashraf Tayea, c, Adel H. Saad ${ }^{b}$
}

\begin{abstract}
Background: Rosiglitazone, an insulin sensitizing agent, has been recently implicated in the control of inflammatory processes and modulation of expression of various cytokines such as tumor necrosis factor (TNF- $\alpha$ ). However, its mechanistic effect of gastric mucosal integrity remains to be elucidated.
\end{abstract}

Methods: The present study was designed to determine effect of rosiglitazone on gastric mucosal lesions induced by indomethacin (IND) in rats. Pyloric ligation was performed for the collection of gastric juice, and gastric ulceration was induced by a single intraperitoneal injection of IND $(30 \mathrm{mg} / \mathrm{kg})$.

Results: IND administration caused a significant decrease in the volume of gastric juice mucin and gastric mucosal nitrite and prostaglandin $\mathrm{E}_{2}\left(\mathrm{PGE}_{2}\right)$ levels. This was accompanied by a significant increase in gastric juice free and total acidity and pepsin activity. In addition, an elevation in the gastric mucosal lipid peroxide and serum TNF- $\alpha$ level was observed. Pretreatment with rosiglitazone $(10 \mathrm{mg} / \mathrm{kg}$, orally, for 1 weeks) resulted in a significant reduction in the elevated gastric mucosal lesions and lipid peroxides levels. This was associated with a marked increase in gastric juice mucin and a reduction in TNF- $\alpha$ level. Moreover, rosiglitazone significantly increased the gastric mucosal total nitrite and $\mathrm{PGE}_{2}$ levels.

Conclusions: Rosiglitazone exerts a gastroprotective effect against IND-induced gastric mucosal lesions and its anti-ulcer effect is mediated via scavenging free radicals, increasing $\mathrm{NO}, \mathrm{PGE}_{2}$ and mucus production in addition to its anti-inflammatory mechanisms. Thus, rosiglitazone could be a relevant drug for patients taking non-

Manuscript accepted for publication December 21, 2009

${ }^{a}$ Department of Pharmacology and Toxicology, Faculty of Pharmacy, Minia University, Egypt

${ }^{b}$ Department of physiology, Faculty of Medicine, Minia University, Egypt

${ }^{\mathrm{c} C}$ Corresponding author: Ashraf taye70@yahoo.com

doi:10.4021/gr2009.12.1328 steroidal anti-inflammatory drugs (NSAIDs) and at high risk of developing gastric ulceration.

Keywords: Rosiglitazone; Gastric ulcer; Indomethacin; TNF- $\alpha$; Lipid peroxides; Nitric oxide

\section{Introduction}

The link between non-steroidal anti-inflammatory drugs (NSAIDs) and the presence of upper gastrointestinal complications has been well established $[1,2]$. Indomethacin (IND), a potent NSAID, was introduced in 1963 for the treatment of rheumatoid arthritis and related diseases. A reduction in the biosynthesis of prostaglandin (PG) through inhibition of cyclooxygenase (COX) is the pharmacological background to both the anti-inflammatory action and the harmful side effects of IND and other NSAIDs [3]. The gastrointestinal adverse effects of NSAIDs, especially in the stomach, are one of the more serious complications in patients taking these drugs [4]. Indeed, IND shows a potent ulcerogenic action in experimental animals [5]. The mechanism by which IND induces gastric injury is generally considered to involve depletion of PGs, yet it has proven to be more complicated and involves multiple, closely interacting elements such as gastric hypermotility, microcirculatory disturbances, neutrophil-endothelial cell interactions and superoxide radicals, in addition to PG deficiency $[6,7]$.

The development of a novel class of insulin-sensitizing drugs, thiazolidinediones, may be considered a significant advance in anti-diabetic therapy. One key mechanism by which theses drugs exert their effects is by activation of the peroxisome proliferator-activated receptor gamma (PPAR- $\gamma$ ), a member of the nuclear receptors family [8]. Recent data suggest that the agonists of these receptors might also have therapeutic potential in the treatment of inflammatory diseases and certain cancers [9].

Rosiglitazone has been recently implicated in the control of inflammatory processes and in the modulation of the expression of various cytokines such as tumor necrosis factor alpha $(\mathrm{TNF}-\alpha)[10,11]$. It has also been shown that rosi- 
glitazone exerts a protective effect against ischemia reperfusion injury in a variety of tissues including the lung [12], the heart [13], and the brain [14]. Furthermore, rosiglitazone has proved its potential effectiveness in treatment of active ulcerative colitis via its anti-inflammatory and antioxidant effects [15]. However its role in stress induced gastric mucosal injury has not been fully emphasized.

The aim of this study was focused on investigation the possible protective effects of rosiglitazone on IND-induced gastric mucosal lesions in adult male rats and the underlying mechanism(s) involved in this setting.

\section{Materials and Methods}

\section{Animals}

Male Wister rats from the local strain weighing $150-200 \mathrm{~g}$ were used. That species was selected due to consistency and reproducibility of gastric ulcer model in it [16]. Rats were housed at room temperature with 12:12 h light/dark cycles. All experiments were performed during the same time of the day to avoid variations due to diurnal rhythm of putative regulators of gastric function. Experiments were conducted in accordance with the guidelines for animal care of the United States Naval Medical Research Centre, Unit No. 3, Abbaseya, Cairo, Egypt, accredited by the Association for Assessment and Accreditation of Laboratory Animal Care international (AAALAC international).

\section{Chemicals}

Indomethacin (IND) and rosiglitazone (Rosi) were purached from Sigma Aldrich (USA).

\section{Pyloric ligation}

All rats were fasted for 24 hours before being subjected to pyloric ligation in mesh bottomed cages to minimize coprophagy, with free access to water except for the last hour before the procedure, rats were deprived of water. Pyloric ligation was carried out in each rat under light ether anesthesia according to the method previously described [17].

\section{Experimental groups}

After pyloric ligation, rats were divided randomly into three experimental groups of 8 rats each. 1, control group, in which rats were left freely wandering in their cages for 3 hours after receiving a single intraperitoneal (IP) injection of $1 \%$ aqueous solution of Tween 80 (vehicle of IND). 2, IND group, in which gastric ulceration was induced by a single IP injection of IND $(30 \mathrm{mg} / \mathrm{Kg})$ [18]. 3, Rosi + IND group, in which rats were given rosiglitazone $(10 \mathrm{mg} / \mathrm{kg}$, IP) for 7 successive days and then gastric ulceration was induced by IND [19].

Three hours after IND administration, blood samples were taken from the heart under ether anesthesia before rats were sacrificed by an ether overdose. Their stomachs were removed, opened along the greater curvature and the gastric content of each stomach was collected. The stomachs were washed with ice-cold saline and examined for gross gastric mucosal lesions using a magnified lens.

\section{Assessment of gastric mucosal lesions}

Gastric mucosal lesions were examined using a magnified lens. The severity of the lesions was expressed in terms of the ulcer index (U.I.) [20]. The lesions were scored as follows: 1 for small petechiae and 2-5 for lesions of 2-5 mm length. The sum of the total scores in each group divided by the number of animals was expressed as the mean U.I. for that group.

\section{Analysis of the gastric juice}

The gastric juice collected from each stomach was centrifuged at $1000 \mathrm{~g}$ for 10 minutes to remove any solid debris and the volume of the supernatant was measured. The supernatant was then analyzed for the determination of free and total acid outputs, pepsin and mucin concentrations.

\section{Determination of free and total acidity of the gastric juice}

The free acidity was determined by titration of a given volume of the gastric juice against $0.1 \mathrm{~N}$ sodium hydroxide up to 5.5 as guided by a $\mathrm{pH}$ meter. The total acidity which is composed of both mineral and organic combined acids in the gastric juice was determined by completing the titration in the above procedure for determining free acidity to $\mathrm{pH} 7$ as guided by the $\mathrm{pH}$ meter [21].

\section{Determination of the proteolytic activity}

The pepsin activity is the major factor involved in the proteolytic activity of gastric secretion. It was determined by a modified spectrophotometric method as previously described [22].

\section{Colorimetric assay for mucins and glycoproteins in gas- tric juice}

It is a sensitive and specific method for saccharides, which is linked via $\mathrm{N}$-acetylgalactosamine through $\mathrm{O}$-glycosidic linkage to serine/threonine in mucins. The method is not affected by the carbohydrates present in other types of glycoproteins [23].

\section{Biochemical analysis of gastric mucosa}


The stomach of each rat was divided into two parts: one part was immersed in IND $(10 \mu \mathrm{g} / \mathrm{ml})$ and was immediately stored at $-80^{\circ} \mathrm{C}$. Subsequently, the gastric mucosa was scraped, homogenized in $2 \mathrm{ml}$ normal saline containing 0.1 $\mathrm{M}$ dithiothreitol and centrifuged at $2000 \mathrm{~g}$ for 10 minutes at room temperature. The supernatant was analyzed for determination of prostaglandin content. The mucosa of the other part of the stomach was also scraped, homogenized in cold potassium phosphate buffer $(0.05 \mathrm{M}, \mathrm{pH} 7.4)$ and centrifuged at $5000 \mathrm{~g}$ for 10 minutes at $4^{\circ} \mathrm{C}$. The supernatant was kept at $-80^{\circ} \mathrm{C}$ for subsequent measurement of lipid peroxides and Nitric oxide. Total protein concentration was also determined using a bicinchoninic acid (BCA) protein assay kit (Pierce Chemicals).

\section{Determination of gastric mucosal prostaglandin $\mathbf{E}_{2}$}

Prostaglandin $\mathrm{E}_{2}\left(\mathrm{PGE}_{2}\right)$ in the gastric mucosa was determined by enzyme-linked immunosorbent assay (ELISA) using PGE assay kit (R\&D Systems, USA) and based on the competitive binding technique in which $\mathrm{PGE}_{2}$ present in a sample competes with a fixed amount of horseradish peroxidase (HRP)-labeled $\mathrm{PGE}_{2}$ for sites on a mouse monoclonal antibody [24].

\section{Determination of gastric mucosal nitric oxide}

Gastric mucosal nitric oxide (NO) was determined using commercially available kits for the Colorimetric determination of total nitrite (Biodiagnostic, Egypt) and based on the enzymatic conversion of nitrate to nitrite by nitrate reductase. The reaction is followed by a colorimetric detection of nitrite as an azo dye product of the Griess [25].

\section{Determination of gastric mucosal lipid peroxides}

Malondialdehyde (MDA) levels in the gastric mucosa were determined as an indicator of lipid peroxidation by thiobar- bituric acid method as previously described [26].

\section{Determination of serum TNF- $\alpha$ level}

Serum TNF- $\alpha$ concentration was measured in this study by enzyme-linked immunosorbent assay (ELISA) using rat TNF- $\alpha$ assay kit (Biosource, USA) following the instructions of the manufacturer and based on previously described method [27].

\section{Statistical analysis}

Data were expressed as mean \pm standard error of the mean (SEM). For comparison between the two means, unpaired Student's t-test and ANOVA for multiple comparisons were used. P value less than 0.05 was considered statistical significance. Statistical analysis was performed using GraphPad Prism 5 (USA).

\section{Results}

\section{Effect of rosiglitazone on gastric juice parameters}

Table 1 shows that IND administration caused significant decrease in the volume of gastric juice and mucin concentration, which was accompanied by significant increase in gastric juice free and total acidity and pepsin activity. Pretreatment with rosiglitazone increased significantly gastric juice mucin concentration, but it failed to produce any significant change in gastric juice free and total acidity or pepsin activity compared to IND group.

Effect of IND on the development of gastric mucosal lesions and its alterations by rosiglitazone pretreatment

Figure 1A shows that IND markedly $(\mathrm{P}<0.01)$ induced a high ulcer index, reaching to about 3 -fold of the control

Table 1. Effect of IND on Gastric Juice Parameters and Their Alteration by Rosiglitazone

\begin{tabular}{llllll}
\hline Groups & $\begin{array}{l}\text { Volume } \\
(\mathbf{m l} / \mathbf{3 h})\end{array}$ & $\begin{array}{l}\text { FAO } \\
(\mathbf{m E q} / \mathbf{3 h})\end{array}$ & $\begin{array}{l}\text { TAO } \\
(\mathbf{m E q} / \mathbf{3 h})\end{array}$ & $\begin{array}{l}\text { Pepsin activity } \\
(\mathbf{m g} / \mathbf{m l})\end{array}$ & $\begin{array}{l}\text { Mucin Content } \\
(\mathbf{m g \%} \text { hexose })\end{array}$ \\
\hline Control & $2.33 \pm 0.23$ & $46.75 \pm 2.82$ & $81.61 \pm 3.28$ & $3.14 \pm 0.23$ & $79.7 \pm 4.05$ \\
IND & $0.81 \pm 0.1^{*}$ & $91.47 \pm 4.14^{*}$ & $101.75 \pm 4.68$ & $8.07 \pm 0.35^{*}$ & $27.26 \pm 2.13^{*}$ \\
IND + Rosi & $0.8 \pm 0.11$ & $87.39 \pm 2.71$ & $91.93 \pm 4.95$ & $7.11 \pm 0.66$ & $69.16 \pm 2.07^{* *}$ \\
\hline
\end{tabular}

Data represent the mean \pm SEM of observations from 8 rats. ${ }^{*} \mathrm{P}<0.05$ significantly different of IND-treated group versus control and IND + Rosi groups; ${ }^{*} \mathrm{P}<0.01$ significantly different of IND + Rosi versus IND. IND: indomethacin; Rosi: rosiglitazone; Total acid outputs; TAO; Free acid outputs, FAO. 

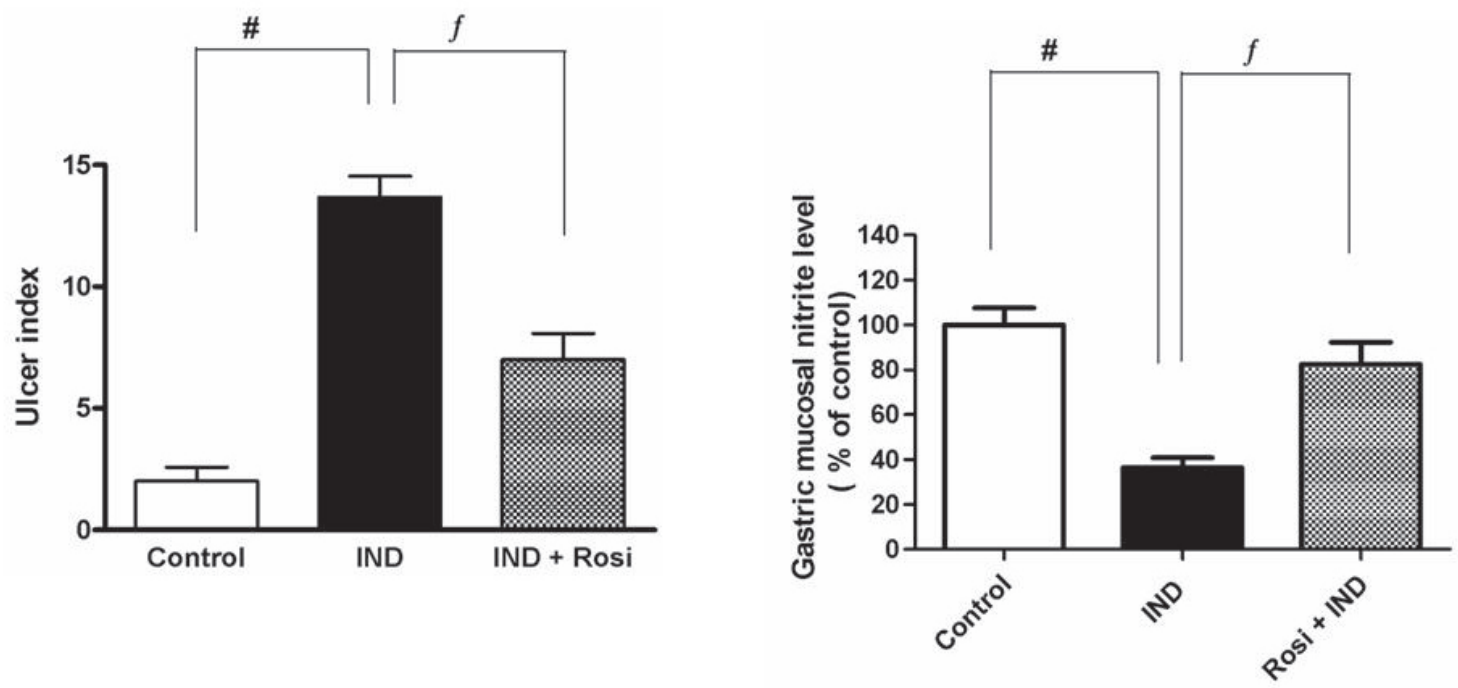

Figure 1. Effect of IND on the development of gastric mucosal lesions and gastric mucosal nitrite level. A, Effect of IND on the development of gastric mucosal lesions. Results are expressed as mean \pm SEM of 8 rats. \# is significantly different from control group; $f$ significantly different from IND at $\mathrm{P}<0.01$ and $\mathrm{P}<0.05$, respectively. $\mathrm{B}$, Effect of IND on gastric mucosal nitrite level. Results are expressed as mean \pm SEM of observations from 8 rats (data are in $\mathrm{pg} / \mathrm{mg}$ wet tissue normalized and expressed as $\%$ of control). \# is significantly different from control group; $f$ is significantly different from IND at $\mathrm{P}<0.01$ and $\mathrm{P}<0.05$, respectively. Symbols as in Table 1.

group. However, rosiglitazone pretreatment profoundly (P $<0.01)$ attenuated the ulcerative lesions and decreased the ulcer index.

\section{Measurement of the gastric mucosal nitrite level in IND- induced gastric ulcer}

IND significantly $(\mathrm{P}<0.01)$ lowered the gastric mucosal nitrite level to one-third of the control level. Pretreatment with rosiglitazone markedly increased the gastric mucosal nitrite level reaching approximately to the normal control level (Fig. 1B).

\section{Effect of rosiglitazone on gastric mucosal lipid peroxides}

IND treatment significantly $(\mathrm{P}<0.001)$ elevated the gastric mucosal MDA concentration (as a biochemical marker of lipid peroxidation). There was 3-fold increase in MDA contents in IND-treated rats compared to control. Pretreatment with rosiglitazone resulted in a significant reduction in the gastric MDA level compared to IND-treated group (Fig. 2A).

\section{Determination of the gastric mucosal $\mathrm{PGE}_{2}$ level}

As illustrated, IND significantly $(\mathrm{P}<0.01)$ lowered the gastric mucosal $\mathrm{PGE}_{2}$ concentrations compared to one-third of the control group. However, rosiglitazone was able to restore the attenuated level of gastric $\mathrm{PGE}_{2}$ almost to the control level (Fig. 2B).

\section{Measurement of the serum TNF- $\alpha$ level}

To verify the anti-inflammatory effect of rosiglitazone on IND-induced gastric ulcer, we measured the serum level of TNF- $\alpha$. Although IND significantly $(\mathrm{P}<0.01)$ increased the serum TNF- $\alpha$ level, about 2-fold compared to that of the control group $(\mathrm{pg} / \mathrm{mL})$, rosiglitazone reduced the elevated TNF- $\alpha$ level near to the normal level (Fig. 3).

\section{Discussion}

Recently, the prescription of combined drugs has become extremely challenging. NSAIDs are one of the most widely used classes of drugs in the world. NSAID-induced gastric ulceration is the major side effect of this kind of drugs [28]. Therefore, drugs that have the potential to reduce NSAIDs side effects should be selected for patients taking NSAIDs concomitantly for treatment of other medical conditions [28].

Rosiglitazone is an antidiabetic drug in the thiazolidinedione class drugs [29]. It acts via activation of the intracellular receptor class of PPAR- $\gamma$ [8]. Apart from its effect on insulin resistance, rosiglitazone appears to have an anti-in- 
A

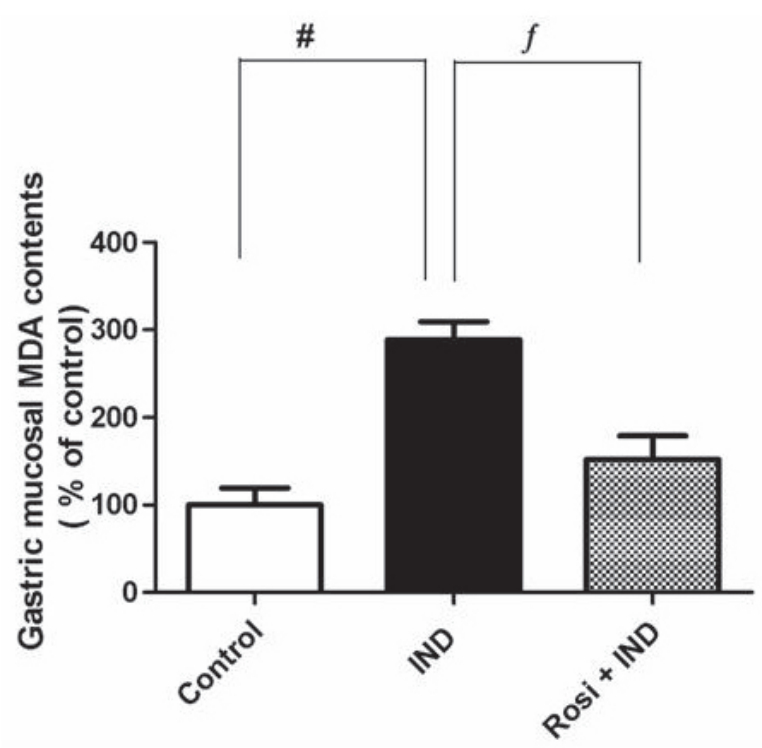

B

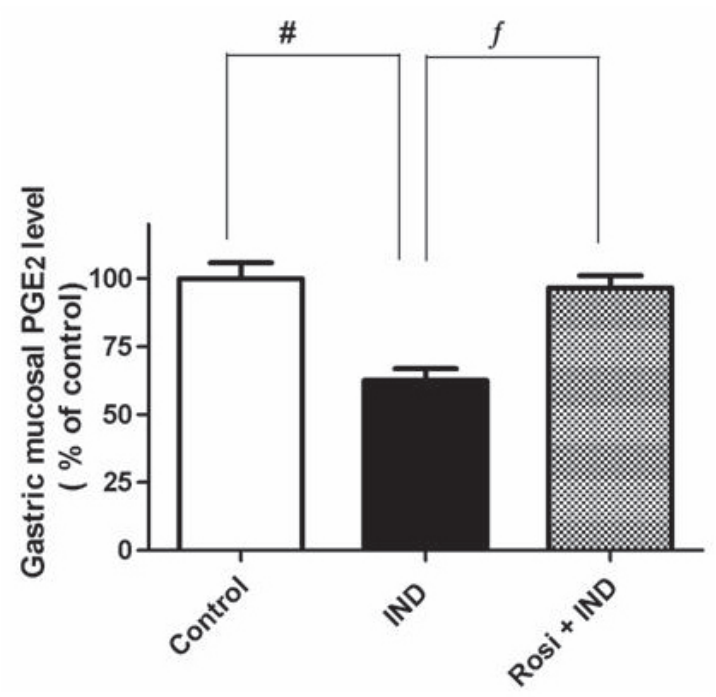

Figure 2. Effect of IND on gastric mucosal malondialdehyde (MDA) and gastric mucosal PGE2 levels. A, Effect of IND on gastric mucosal MDA level. Results are expressed as mean \pm SEM of observations from 8 rats (data are in pg/mg wet tissue normalized and expressed as $\%$ of control). \# is significantly different from control group; $f$ is significantly different from IND at $P<0.001$ and $\mathrm{P}<0.05$, respectively. B, Effect of IND on gastric mucosal PGE2 level. Results are expressed as mean \pm SEM of observations from 8 rats (data are in $\mathrm{pg} / \mathrm{mg}$ wet tissue normalized and expressed as \% of control). \# is significantly different from control group; $f$ is significantly different from IND at $\mathrm{P}<0.01$ and $\mathrm{P}<0.05$, respectively. Symbols as in Table 1.

flammatory and antioxidant effects in a variety of inflammatory conditions including the gut $[11,14,30]$. Therefore, this study was an attempt to investigate the possible gastroprotective effect of rosiglitazone on IND-induced gastric ulcer in rats. If proved so, rosiglitazone could have an advantage over other antidiabetic drugs by providing those patients additional protection against gastric ulceration if they are at high risk due to concomitant administration of NSAIDs.

In the present study, IND administration induced severe gastric mucosal ulcerations, which were accompanied by significant increase in gastric acidity, pepsin activity, MDA and TNF- $\alpha$ with concomitant reduction in NO, mucin and $\mathrm{PGE}_{2}$ levels compared to the control rats. The gastrotoxic effects of NSAIDs, including IND are attributed to the non-selective inhibition of cyclooxygenases (COX1 and COX2) with subsequent reduction in PGs production, which are believed to have potent anti-ulcer and cytoprotective properties $[2,4$, 31]. Ulceration due to NSAIDs could also be due to their ability to induce reactive oxygen metabolites, which may intern promote lipid peroxidation and gastric damage [32].

In the current study, rosiglitazone pretreatment reduced significantly the ulcerative lesions induced by IND, which were associated with significant decrease in both lipid peroxides and TNF- $\alpha$ level together with concomitant increase in $\mathrm{NO}, \mathrm{PGE}_{2}$ and mucin levels compared to non-treated IND group. These results suggest that the protective effect of rosiglitazone may have multiple components in its actions.

Free radicals production has been reported to play a fundamental role in the pathogenesis of NSAIDs-induced gastric damage [33]. In the present study, the toxic effects of these reactive oxygen species (ROS) were evidenced by significant increase in MDA levels, which was associated with the provocation of ulcerative lesions. Rosiglitazone pretreatment significantly decreased lipid peroxides levels, which was accompanied with marked attenuation in the gastric lesions compared to non-treated IND group. Rosiglitazone was reported to enhance the expression of antioxidant enzymes namely xanthine oxidase and superoxide dismutase [34]. This increase in the antioxidant activity, in turn counteracts the deleterious effects of ROS with subsequent attenuation of mucosal damage. Therefore, the antioxidant property of rosiglitazone could be a part of its protective effect against IND-induced gastric ulceration.

NSAIDs could be proinflammatory by increasing TNF- $\alpha$ [35], which was confirmed in the present study. IND administration markedly increased the plasma level of the TNF- $\alpha$, this effect was reversed by rosiglitazone pretreatment. TNF- $\alpha$ is a potent stimulator of neutrophil infiltration and plays a 


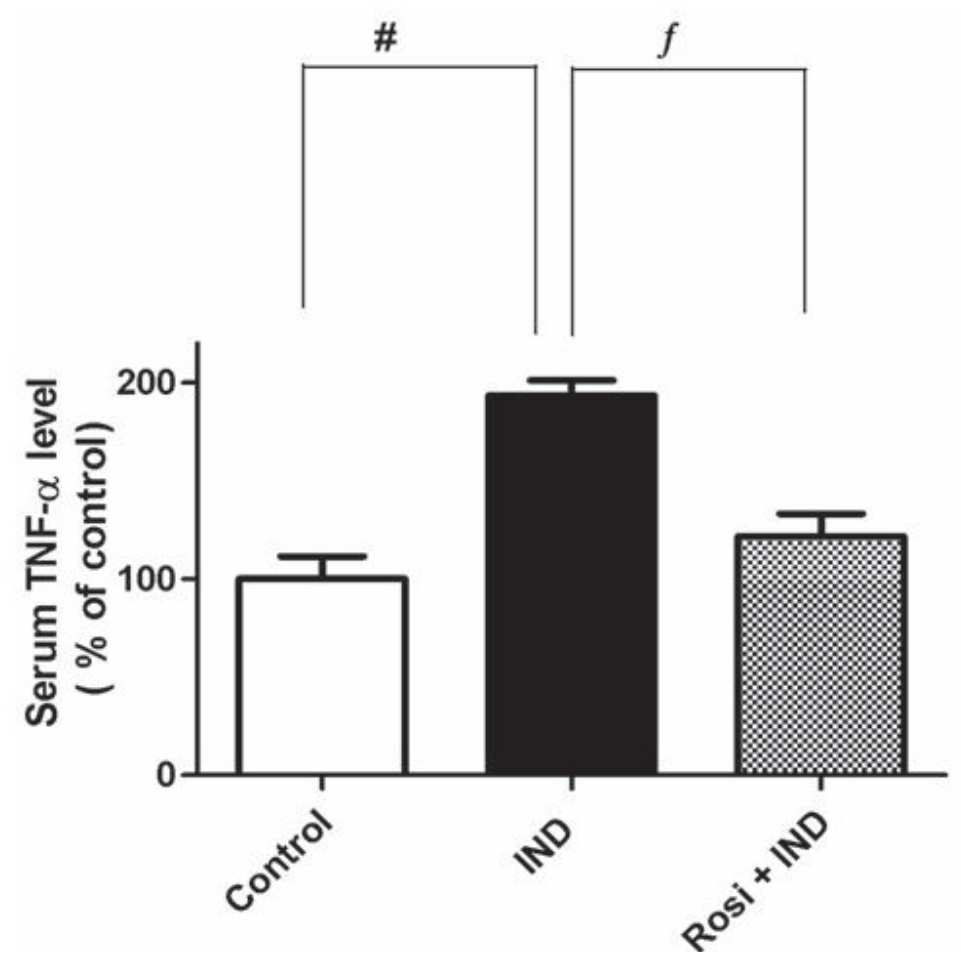

Figure 3. Effect of IND on the serum TNF- $\alpha$ level. Results are expressed as mean \pm SEM of observations from 8 rats (data are in $\mathrm{pg} / \mathrm{mL}$ normalized and expressed as $\%$ of control). \# is significantly different from control group; $f$ is significantly different from IND at $P<0.01$ and $P<0.05$, respectively. Symbols as in Table 1.

crucial role in the progression of ulcer injury via production of the injurious ROS [36]. The reduction in TNF- $\alpha$ by rosiglitazone, in turn inhibits neutrophil infiltration with subsequent oxidative burst of reactive oxygen species resulting in attenuation of the ulcerative lesions [37]. Previous studies reported that rosiglitazone exerts a potent an anti-inflammatory effect by inhibiting the expression of TNF- $\alpha$ in a variety of tissues including the stomach $[34,38]$. Therefore, these findings provide an additional evidence for the gastroprotective effects of rosiglitazone against IND-induced gastric ulceration, which could be mediated by its anti-inflammatory action via inhibition of inflammatory cytokines (e.g. TNF- $\alpha$ ) production as well as inhibition of ROS production.

NO plays a critical role in modulating several components of gastric mucosal defense including gastric mucosal blood flow, neutrophil adhesion and mucus secretion [39], thus affording gastric protection. Earlier studies revealed that endogenous NO released from vascular endothelium, sensory nerves or gastric epithelium cooperates with endogenous prostaglandins in the maintenance of gastric mucosa integrity and microcirculation [40].

IND administration significantly decreased the tissue nitrite level compared to control group, which was associated with ulcerative lesions. Since NO is the endothelium derived relaxing factor, reduction its level might contribute to reduce mucosal blood flow by the vasoconstriction response with subsequent gastric damage [41]. Rosiglitazone pretreatment markedly increased the NO level in gastric mucosa that resulted in attenuation of gastric lesions. Recent studies have shown that PPAR- $\gamma$ agonist pioglitazone (same class as rosiglitazone) increases NO production and enhances ulcer healing, this effect was abolished by pretreatment of L-NNA, an NO synthase inhibitor [42]. These findings suggest that rosiglitazone could have similar stimulatory effect on $\mathrm{NO}$, which was confirmed in our study. The increased NO level by Rosiglitazone could be attributed to the activation of NO synthase by phosphorylation and increase NO bioavailability [43]. Based on these findings, increased production of NO could be a potential target for the gastroprotective effect of rosiglitazone in this study.

Inhibition of gastric prostaglandin (PGs) synthesis is central to the ability of NSAIDs to cause gastric damage [2]. Subsequently, agents that interfere with the ability of NSAIDs to suppress gastric PGs synthesis will reduce the ability of those agents to cause damage. In the present study, IND administration caused a marked reduction in $\mathrm{PGE}_{2}$ level, which was associated with the development of gastric ulceration. Rosiglitazone pretreatment reversed the condition and increased significantly the $\mathrm{PGE}_{2}$ level with significant attenuation in the ulcerative lesions, compared to 
the non-treated IND group. Previous studies have shown that the rosiglitazone-induced prostaglandin production could be mediated by influences at the level of both cyclo-oxygenase-2 expression and substrate formation [44] Another possible mechanism for increased $\mathrm{PGE}_{2}$ level may be explained in part by the stimulatory effect of rosiglitazone on NO production [43]. It was reported that $\mathrm{NO}$ increased $\mathrm{PGE}_{2}$ synthesis in vivo through cGMP-independent mechanism and it was assumed that NO might regulate the release and/or the synthesis of $\mathrm{PGE}_{2}$ in the stomach after damage [45].

The secretion of mucus, one of the several defensive factors in the gastrointestinal tract [46] is another possible target for the action of rosiglitazone. IND caused a significant reduction in mucus secretion, which was reversed by rosiglitazone. Mucus secretion is physiologically regulated by both $\mathrm{NO}$ [47] and $\mathrm{PGE}_{2}$ [42], and since both $\mathrm{NO}$ and $\mathrm{PGE}_{2}$ were significantly increased by rosiglitazone, it will be expected to find a concomitant increase in mucus level with subsequent improvement in ulcerative lesions, which was confirmed in the present study.

On the other hand, the genesis of ulcer requires acid, peptic activity and breakdown of mucosal defense mechanism [48]. However, rosiglitazone failed to produce any significant change in gastric acidity or pepsin activity compared to non-treated IND group suggesting that the gastroprotective effect of rosiglitazone does not involve attenuation of aggressive factors, rather, it acts on strengthening the defensive factors such as $\mathrm{NO}, \mathrm{PGE}_{2}$ and mucus barrier.

In conclusion, rosiglitazone protects against IND-induced ulcer and this effect appears to be multifactorial. The mechanisms of this protective effect include its ability to increase $\mathrm{NO}, \mathrm{PGE}_{2}$ as well as mucus secretion. In addition, the antioxidant properties of rosiglitazone seem to play a crucial role in the gastroprotection via scavenging free radicals. Thus, this study considers rosiglitazone as a more relevant anti-diabetic therapy for patients who are at risk of gastric ulcers that were induced by the frequent use NSAIDs. Thus, rosiglitazone could provide an extra benefit for patients taking NSAIDs and at high risk of developing gastric ulceration.

\section{References}

1. Weil J, Langman MJ, Wainwright P, Lawson DH, Rawlins M, Logan RF, Brown TP, et al. Peptic ulcer bleeding: accessory risk factors and interactions with non-steroidal anti-inflammatory drugs. Gut 2000;46(1):27-31.

2. Lazzaroni M, Porro GB. Management of NSAID-induced gastrointestinal toxicity: focus on proton pump inhibitors. Drugs 2009;69(1):51-69.

3. Wallace JL. Nonsteroidal anti-inflammatory drugs and gastroenteropathy: the second hundred years. Gastroenterology 1997;112(3):1000-1016.
4. Hawkey CJ, Langman MJ. Non-steroidal anti-inflammatory drugs: overall risks and management. Complementary roles for COX-2 inhibitors and proton pump inhibitors. Gut 2003;52(4):600-608.

5. Filaretova L, Tanaka A, Miyazawa T, Kato S, Takeuchi K. Mechanisms by which endogenous glucocorticoid protects against indomethacin-induced gastric injury in rats. Am J Physiol Gastrointest Liver Physiol 2002;283(5):G1082-1089.

6. Takeuchi K, Okada M, Niida H, Okabe S. Possible mechanisms involved in gastric hypermotility caused by indomethacin in the rat. Role of glycoprivic response. Dig Dis Sci 1990;35(8):984-992.

7. Beck PL, Xavier R, Lu N, Nanda NN, Dinauer M, Podolsky DK, Seed B. Mechanisms of NSAID-induced gastrointestinal injury defined using mutant mice. Gastroenterology 2000;119(3):699-705.

8. Zieleniak A, Wojcik M, Wozniak LA. Structure and physiological functions of the human peroxisome proliferator-activated receptor gamma. Arch Immunol Ther Exp (Warsz) 2008;56(5):331-345.

9. Pershadsingh HA. Peroxisome proliferator-activated receptor-gamma: therapeutic target for diseases beyond diabetes: quo vadis? Expert Opin Investig Drugs 2004;13(3):215-228.

10. Murphy GJ, Holder JC. PPAR-gamma agonists: therapeutic role in diabetes, inflammation and cancer. Trends Pharmacol Sci 2000;21(12):469-474.

11. Mohanty P, Aljada A, Ghanim H, Hofmeyer D, Tripathy D, Syed T, Al-Haddad W, et al. Evidence for a potent antiinflammatory effect of rosiglitazone. J Clin Endocrinol Metab 2004;89(6):2728-2735.

12. Cuzzocrea S, Pisano B, Dugo L, Ianaro A, Maffia P, Patel NS, Di Paola R, et al. Rosiglitazone, a ligand of the peroxisome proliferator-activated receptor-gamma, reduces acute inflammation. Eur J Pharmacol 2004;483(1):7993.

13. Yue Tl TL, Chen J, Bao W, Narayanan PK, Bril A, Jiang W, Lysko PG, et al. In vivo myocardial protection from ischemia/reperfusion injury by the peroxisome proliferator-activated receptor-gamma agonist rosiglitazone. Circulation 2001;104(21):2588-2594.

14. Yi JH, Park SW, Brooks N, Lang BT, Vemuganti R. PPARgamma agonist rosiglitazone is neuroprotective after traumatic brain injury via anti-inflammatory and anti-oxidative mechanisms. Brain Res 2008;1244(164172.

15. Lewis JD, Lichtenstein GR, Deren JJ, Sands BE, Hanauer SB, Katz JA, Lashner B, et al. Rosiglitazone for active ulcerative colitis: a randomized placebo-controlled trial. Gastroenterology 2008;134(3):688-695.

16. Weischer $\mathrm{CH}$, Thiemer K. A method for induction of cold, indomethacin and restraint ulcers in rats. Methods Find Exp Clin Pharmacol 1983;5(5):315-319. 
17. Alumets J, Ekelund M, Hakanson R, Hedenbro J, Rehfeld JF, Sundler F, Vallgren S. Gastric acid response to pylorus ligation in rats: is gastrin or histamine involved? J Physiol 1982;323:145-156.

18. Khattab MM, Gad MZ, Abdallah D. Protective role of nitric oxide in indomethacin-induced gastric ulceration by a mechanism independent of gastric acid secretion. Pharmacol Res 2001;43(5):463-467.

19. Johns DG, Ao Z, Eybye M, Olzinski A, Costell M, Gruver S, Smith SA, et al. Rosiglitazone protects against ischemia/reperfusion-induced leukocyte adhesion in the zucker diabetic fatty rat. J Pharmacol Exp Ther 2005;315(3):1020-1027.

20. Biswas K, Bandyopadhyay U, Chattopadhyay I, Varadaraj A, Ali E, Banerjee RK. A novel antioxidant and antiapoptotic role of omeprazole to block gastric ulcer through scavenging of hydroxyl radical. J Biol Chem 2003;278(13):10993-11001.

21. Hara N, Hara Y, Natsume Y, Goto Y. Gastric hyperacidity and mucosal damage caused by hypothermia correlate with increase in GABA concentrations of the rat brain. Eur J Pharmacol 1991;194(1):77-81.

22. Vagne M, Daniere S, Perret G, Desvigne A. [Determination of the proteolytic activity of gastric juice by an automatic method]. Pathol Biol (Paris) 1974;22(4):359-364.

23. Bhavanandan VP, Sheykhnazari M, Devaraj H. Colorimetric determination of $\mathrm{N}$-acetylhexosamine-terminating O-glycosidically linked saccharides in mucins and glycoproteins. Anal Biochem 1990;188(1):142-148.

24. Wang X, Stocco DM. The decline in testosterone biosynthesis during male aging: a consequence of multiple alterations. Mol Cell Endocrinol 2005;238(1-2):1-7.

25. Dawson VL. Nitric oxide: role in neurotoxicity. Clin Exp Pharmacol Physiol 1995;22(4):305-308.

26. Girgin F, Tuzun S, Demir A, Kuralay F, Ozutemiz O, Tanyalcin T. Cytoprotective effects of trimetazidine in carmustine cholestasis. Exp Toxicol Pathol 1999;51(45):326-329.

27. $\mathrm{Su}$ GL, Goyert SM, Fan MH, Aminlari A, Gong KQ, Klein RD, Myc A, et al. Activation of human and mouse Kupffer cells by lipopolysaccharide is mediated by CD14. Am J Physiol Gastrointest Liver Physiol 2002;283(3):G640-645.

28. Hawkins C, Hanks GW. The gastroduodenal toxicity of nonsteroidal anti-inflammatory drugs: a review of the literature. J Pain Symptom Manage 2000;20(2):140151.

29. Kalaitzidis RG, Sarafidis PA, Bakris GL. Effects of thiazolidinediones beyond glycaemic control. Curr Pharm Des 2009;15(5):529-536.

30. Bragt MC, Plat J, Mensink M, Schrauwen P, Mensink RP. Anti-inflammatory effect of rosiglitazone is not reflected in expression of NFkappaB-related genes in peripheral blood mononuclear cells of patients with type 2 diabetes mellitus. BMC Endocr Disord 2009;9(8.

31. Konturek SJ, Konturek PC, Brzozowski T. Prostaglandins and ulcer healing. J Physiol Pharmacol 2005;56 (Suppl):5-31.

32. Naito Y, Yoshikawa T, Yoshida N, Kondo M. Role of oxygen radical and lipid peroxidation in indomethacininduced gastric mucosal injury. Dig Dis Sci 1998;43(9 Suppl):30S-34S.

33. Kwiecien S, Brzozowski T, Konturek SJ. Effects of reactive oxygen species action on gastric mucosa in various models of mucosal injury. J Physiol Pharmacol 2002;53(1):39-50.

34. Villegas I, Martin AR, Toma W, de la Lastra CA. Rosiglitazone, an agonist of peroxisome proliferator-activated receptor gamma, protects against gastric ischemia-reperfusion damage in rats: role of oxygen free radicals generation. Eur J Pharmacol 2004;505(1-3):195-203.

35. Kast RE. Non-steroidal anti-inflammatory drugs might also be pro-inflammatory by increasing tumor necrosis factor. Biomed Pharmacother 2000;54(3):168-169.

36. Ding SZ, Lam SK, Yuen ST, Wong BC, Hui WM, Ho J, Guo X, et al. Prostaglandin, tumor necrosis factor alpha and neutrophils: causative relationship in indomethacininduced stomach injuries. Eur J Pharmacol 1998;348(23):257-263.

37. Sanchez-Hidalgo M, Martin AR, Villegas I, Alarcon De La Lastra C. Rosiglitazone, an agonist of peroxisome proliferator-activated receptor gamma, reduces chronic colonic inflammation in rats. Biochem Pharmacol 2005;69(12):1733-1744.

38. Takagi T, Naito Y, Ichikawa H, Tomatsuri N, Katada K, Isozaki Y, Kuroda M, et al. A PPAR-gamma ligand, 15-deoxy-Delta12,14-prostaglandin J(2), inhibited gastric mucosal injury induced by ischemia-reperfusion in rats. Redox Rep 2004;9(6):376-381.

39. Calatayud S, Barrachina D, Esplugues JV. Nitric oxide: relation to integrity, injury, and healing of the gastric mucosa. Microsc Res Tech 2001;53(5):325-335.

40. Brzozowski T. Experimental production of peptic ulcer, gastric damage and cancer models and their use in pathophysiological studies and pharmacological treatment-Polish achievements. J Physiol Pharmacol 2003;54 (Suppl):99-126.

41. Tripp MA, Tepperman BL. Effect of nitric oxide on integrity, blood flow and cyclic GMP levels in the rat gastric mucosa: modulation by sialoadenectomy. Br J Pharmacol 1995;115(2):344-348.

42. Brzozowski T, Konturek PC, Pajdo R, Kwiecien SN, Konturek S, Targosz A, Burnat G, et al. Agonist of peroxisome proliferator-activated receptor gamma (PPARgamma): a new compound with potent gastroprotective and ulcer healing properties. Inflammopharmacology 2005;13(1-3):317-330.

43. Boyle JG, Logan PJ, Ewart MA, Reihill JA, Ritchie 
SA, Connell JM, Cleland SJ, et al. Rosiglitazone stimulates nitric oxide synthesis in human aortic endothelial cells via AMP-activated protein kinase. J Biol Chem 2008;283(17):11210-11217.

44. Bishop-Bailey D, Warner TD. PPARgamma ligands induce prostaglandin production in vascular smooth muscle cells: indomethacin acts as a peroxisome proliferator-activated receptor-gamma antagonist. Faseb J 2003;17(13):1925-1927.

45. Takeuchi K, Suzuki K, Araki H, Mizoguchi H, Sugamoto $\mathrm{S}$, Umdeda $\mathrm{M}$. Roles of endogenous prostaglandins and nitric oxide in gastroduodenal ulcerogenic responses induced in rats by hypothermic stress. J Physiol Paris 1999;93(5):423-431.

46. Werther JL. The gastric mucosal barrier. Mt Sinai J Med 2000;67(1):41-53.

47. Brown JF, Hanson PJ, Whittle BJ. Nitric oxide donors increase mucus gel thickness in rat stomach. Eur J Pharmacol 1992;223(1):103-104.

48. Hase T, Anderson PR, Mehlman B. Significance of gastric secretory changes in the pathogenesis of stress ulcers. Am J Dig Dis 1975;20(5):443-449. 